\title{
10
}

\section{CONTRIBUIÇÃO DA PEDAGOGIA HISTÓRICO-CRÍTICA PARA O DESENVOLVIMENTO DA PRÁTICA EDUCATIVA: EDUCAÇÃO ESTÉTICA *1}

Thiago Xavier de Abreu

A busca dos fundamentos específicos para cada área do conhecimento no interior da pedagogia histórico-crítica é um dos desafios colocados à real efetivação desta corrente educacional como prática transformadora. Compreender a importância de cada conteúdo escolar perante a prática social é uma condição para que possamos entender suas contribuições para a formação humana, possibilitando novas formas de organização social, formas mais humanizadoras. É a partir deste quadro que podemos observar as contribuições da arte para o desenvolvimento da prática educativa na pedagogia histórico-crítica.

\section{Educação, ciência e arte como prática social}

Um possível ponto de partida para a análise das especificidades da arte como conteúdo escolar é o estabelecimento de suas relações com a categoria central que sustenta as bases filosóficas da pedagogia históricocrítica, o trabalho, a atividade vital humana. Os elementos essenciais da atividade propriamente humana sobre a realidade objetiva emergem claramente se a colocamos em contraste com a atividade animal. Para Marx:

O animal é imediatamente um com sua atividade vital. Não se distingue dela. É ela. O homem faz da sua atividade vital mesma um objeto da sua vontade e da sua consciência. Ele tem atividade vital consciente. Esta não é uma determinante (Bestimmtheit) com a qual ele coincide imediatamente. A atividade vital consciente distingue o homem imediatamente da atividade vital animal. Justamente, [e] só por isso,

*DOI - 10.29388/978-65-86678-91-8-0-f.215-238

${ }^{1}$ Texto elaborado a partir da "live" realizada no interior da disciplina/curso de extensão "PHC e prática transformadora" pelo canal do HISTEDBR no youtube em 26/11/2020. 
ele é um ser genérico. Ou ele somente é um ser consciente, isto é, a sua própria vida lhe é objeto, precisamente porque é um ser genérico. Eis porque a sua atividade é atividade livre (MARX, 2010, p. 84, grifos no original).

O trabalho é caracterizado por Marx como atividade teleológica da produção dos meios de satisfação de suas necessidades. Esse caráter teleológico do trabalho significa a transferência de sua intencionalidade para a natureza, tornando-a uma natureza humanizada, ou melhor, tornando-a seu corpo inorgânico, e os instrumentos por ele produzidos, seus órgãos (MARX, 2010, 2011). Ao produzirem os meios para a satisfação de suas necessidades - primeiro ato histórico - os seres humanos engendram em si novas necessidades (MARX; ENGELS, 2007, p. 33); necessidades não naturais, mas propriamente sociais, surgidas a partir da mediação da atividade humana previamente objetivada na realidade. Daí o caráter genérico do trabalho, isto é, o fato de que seus elementos essenciais se definem somente a partir das relações entre a atividade prática individual e a totalidade das relações humanas historicamente objetivadas, ou, nas palavras de Marx, "atuando assim sobre a natureza externa e modificando-a, ao mesmo tempo modifica sua própria natureza" (MARX, 2013, p. 211).

A natureza livre e universal da atividade humana significa precisamente que, no processo de trabalho, não somente são criadas novas necessidades, mas também novas forças, novas possibilidades, gerando um contínuo enriquecimento da realidade objetiva. Somente deste ponto de vista podemos compreender, numa perspectiva imanente à própria atividade humana, o surgimento de necessidades "espirituais", ou seja, não diretamente ligadas ao atendimento de necessidades materiais básicas e imediatas do metabolismo ser humano/natureza. Discutindo o desenvolvimento histórico da atividade consciente, Márkus expõe:

Além do surgimento do pensamento conceitual, que em sua forma elementar ocorreu no curso da antropogênese paralela e nas primeiras formas de sociedade, o desenvolvimento da consciência humana significa, antes de tudo, o surgimento e o desdobramento histórico desses sistemas independentes de objetivação que se tornam diferenciados e, ao mesmo tempo, separados do pensamento cotidiano como áreas particulares da produção 'espiritual' mental-intelectual (geistige Produktion). É desta forma que, no curso da história das for- 
mas superiores de realização intelectual, diferentes umas das outras em seus objetos e em sua relação com seus objetos - as formas artística, religiosa e teórico-científica de apropriação da realidade - evoluíram, a partir da apropriação 'prático-mental' cotidiana do mundo. $E$, assim, à medida que vão se desenvolvendo, fazem novas exigências sociais sobre os indivíduos nelas envolvidos, fazendo com que esses cultivem em si novas capacidades psíquicas e carências (MÁRKUS, 2015, p. 80).

Márkus nos aponta que o curso histórico da atividade humana corresponde não somente ao progressivo desenvolvimento e domínio das necessidades "espirituais", mas também à especialização dessa atividade em esferas particulares, em "sistemas independentes de objetivação". Uma destas esferas é a que corresponde ao processo de formação dos indivíduos como seres sociais, ou seja, ao fenômeno educacional. Nesse sentido, a educação é entendida como algo que progressivamente vai se constituindo como uma atividade específica no interior da totalidade da prática social. Nas palavras de Saviani, "trata-se da conceituação de educação como uma 'atividade mediadora no seio da prática social global'”' (SAVIANI, 2018, p. 59).

É deste prisma teórico-metodológico que se pode conceber a essência do fenômeno educativo em dialética com a historicidade da prática humana. Isso significa considerar o trabalho educativo tanto em seu aspecto ontológico, isto é, como "ato de produzir, direta e intencionalmente, em cada indivíduo singular, a humanidade que é produzida histórica e coletivamente pelo conjunto dos homens" (SAVIANI, 2008, p. 13), quanto em seus diferentes momentos históricos de desenvolvimento. Nas sociedades pré-capitalistas a formação intelectual caminhava de maneira relativamente paralela aos processos de produção da vida material, ao passo que na sociedade moderna, estruturada sob o modo de produção capitalista, "o eixo do processo produtivo deslocou-se do campo para cidade, da agricultura para indústria, a qual converteu o saber, de potência espiritual (intelectual) em potência material, isto é, transformou o saber (a ciência) em meio de produção" (SAVIANI, 1991, p. 86). Esse deslocamento para o centro do sistema produtivo exigiu da sociedade formas institucionalizadas de socialização dos saberes sistematizados, levando ao surgimento dos sistemas escolares. Consequentemente, para a pedagogia histórico-crítica, a educação escolar representa a forma historicamente mais desenvolvida do trabalho 
educativo, ou seja, a escola é entendia como expressão do domínio exercido pelo ser humano sobre uma dimensão da sua própria prática social, a dimensão educativa, exercendo uma atividade consciente sobre ela. Para Duarte:

Considero que a análise realizada por Saviani vai além do processo de institucionalização da educação. Tal institucionalização significa que a produção e reprodução do ser da sociedade passam, ao longo do processo histórico, a requerer a existência de um tipo específico de atividade humana, voltado para a formação dos indivíduos. Em outras palavras, a partir do capitalismo torna-se uma necessidade do ser da sociedade a elevação do processo educativo, do nível de processo educativo em si para o nível de processo educativo para si (DUARTE, 2012, p. 44).

Outras duas esferas de atividade humana que acompanham esse progressivo movimento de enriquecimento e especialização da prática social são as das práticas científicas e artísticas. Para o filósofo György Lukács, ambas são "polos da recepção subjetiva do mundo" (LUKÁCS, 1968, p. 297), e participam do processo de formação da consciência como reflexos da realidade objetiva, ou como formas de reprodução da realidade objetiva na subjetividade 2 . Em linhas gerais, para Lukács, a ciência desantropomorfiza a realidade para a construção da consciência, isto é, retira dela toda a carga subjetivista, fruto de uma leitura meramente individual da realidade, constituindo um reflexo que desvela o real como ele é em si na objetivamente. Já a arte se constitui como um reflexo antropomórfico da realidade objetiva, isto é, uma esfera de objetivação que se apropria das formas deste mundo para criar reproduções da realidade que não almejam ser a realidade em si, mas sim mostrar, por meio dessa reprodução, aspectos humanos presentes na prática social para o próprio ser humano. Mas a especialização dessas diferentes esferas de atividade

\footnotetext{
${ }^{2}$ É interessante notar o diálogo entre a perspectiva de reflexo de Lukács e a tradição da psicologia soviética, que fundamenta os princípios psicológicos da pedagogia histórico-crítica. Uma vez que ambas se apoiam nas bases filosóficas marxistas, bem como o princípio epistemológico central materialista de que a realidade objetiva existe independentemente da consciência, seus posicionamentos acerca da consciência humana convergem no sentido de entendê-la como um reflexo da realidade objetiva, ou, para a psicologia histórico-cultural, a imagem subjetiva da realidade objetiva (MARTINS, 2013).
} 
humana também é resultado de um desenvolvimento histórico; de acordo com Bela Kiralyfalvi:

Lukács acredita que nas sociedades primitivas não existia separação nos modos de reflexo. O que mais tarde se separa em reflexos científico, religioso e artístico, distintamente diferentes um do outro, são, nesta fase de desenvolvimento, indistinguíveis. O ritual primitivo contém elementos científicos (utilitários), religiosos (mágicos) ${ }^{3}$ e artísticos (formais). O criador é cientista, sacerdote (mago) e artista, todos ao mesmo tempo, fazendo o que ele faz para o bem-estar da comunidade, para a sobrevivência. A partir daí, o primeiro estágio de desenvolvimento da arte consiste na separação da reflexão antropomórfica (arte e religião), da reflexão (científica) desantropomórfica. O segundo estágio é uma divisão dentro da categoria de reflexão antropomórfica, isto é, a separação da arte da religião [...].

Resumidamente, a diferença entre arte e ciência é que "a arte cria o mundo do homem, sempre e exclusivamente... Em todas as facetas deste reflexo (ao contrário do reflexo científico), o homem está presente como determinante: na arte o mundo fora do homem só ocorre como um elemento mediador de preocupações, ações e sentimentos humanos". A diferença essencial entre arte e religião é que na arte "a imagem refletida da realidade é concebida como reflexo, enquanto a magia e a religião atribuem o status da realidade objetiva aos seus sistemas de reflexão e exigem crença neles" (KIRALYFALVI, 1983, p. 124).

O desenvolvimento histórico e a especialização dessas diferentes esferas da prática social - as formas científica e artística de reflexo da realidade objetiva e a atividade especificamente voltada para a formação da humanidade nos seres humanos (trabalho educativo) - nos levam a pelo menos duas conclusões. A primeira, a de que o trabalho educativo que acontece na educação escolar é diferente de outros processos educacionais que possam ocorrer no cotidiano; existem processos educativos fora da escola, mas a educação que ocorre na escola é qualitativamente diferente,

\footnotetext{
${ }^{3}$ Apesar de que neste excerto Kiralyfalvi trate a magia e a religião de forma semelhante, Lukács faz uma relativa distinção entre estas duas atividades. Para Lukács, a magia está mais diretamente ligada ao esforço por dominar a natureza. Ela surge antes da religião, mas não desaparece com o surgimento da religião, que incorpora a magia em seus rituais. Sobre essa diferença, veja Lukács (1966, pp. 104-105).
} 
porque se constitui como uma relação consciente com o trabalho educativo.

A segunda é a de que a arte como prática social é diferente da arte como conteúdo escolar. Assim, cabe diferenciar, na prática social, a atividade da produção da arte em si mesma da atividade de produção da humanização dos indivíduos pela arte. Naquela, a finalidade é propriamente estética; nesta, é educativa. É nesse sentido que Saviani, referindo-se aos objetos das ciências humanas, diferencia os diversos conteúdos em si mesmos do trabalho educativo com esses conteúdos:

Com efeito, se a educação, pertencendo ao âmbito do trabalho nãomaterial, tem a ver com ideias, conceitos, valores, símbolos, hábitos, atitudes, habilidades, tais elementos, entretanto, não lhe interessam em si mesmos, como algo exterior ao homem.

Nessa forma, isto é, considerados em si mesmos, como algo exterior ao homem, esse elementos constituem o objeto de preocupação das chamadas ciências humanas, ou seja, daquilo que Dilthey denomina "ciências do espírito" por oposição às "ciências da natureza". Diferentemente, do ponto de vista da educação, ou seja, da perspectiva da pedagogia entendida como ciência da educação, esses elementos interessam enquanto é necessário que os homens os assimilem, tendo em vista a constituição de algo como uma segunda natureza (SAVIA$\mathrm{NI}, 2008$, p. 13).

\section{A arte na educação escolar}

A análise acima nos fornece elementos importantes para refletirmos sobre a presença da arte na educação escolar. Caminhando em direção às especificidades dos fenômenos educacionais e artísticos no interior da totalidade da prática social podemos estabelecer mais claramente as diferentes relações entre o trabalho educativo e a arte. Avancemos um pouco mais nas especificidades do trabalho educativo. De acordo com Saviani

Assim, o objeto da educação diz respeito, de um lado, à identificação dos elementos culturais que precisam ser assimilados pelos indivíduos da espécie humana para que eles se tornem humanos e, de outro lado, e concomitantemente, à descoberta das formas mais adequadas para atingir esse objetivo. 
Quanto ao primeiro aspecto (a identificação dos elementos culturais que precisam ser assimilados) trata-se de distinguir entre o essencial e o acidental, o principal e o secundário, o fundamental e o assessório. Aqui me parece de grande importância, em pedagogia, a noção de "clássico". O clássico não se confunde com o tradicional e também não se opõe, necessariamente, ao moderno e muito menos ao atual. O clássico é aquilo que se firmou como fundamental, como essencial. Pode, pois, constituir-se num critério útil para a seleção dos conteúdos do trabalho pedagógico.

Quanto ao segundo aspecto (a descoberta das formas adequadas de desenvolvimento do trabalho pedagógico), trata-se da organização dos meios (conteúdos, espaço, tempo e procedimentos) através dos quais, progressivamente, cada indivíduo singular realize, na forma de segunda natureza, a humanidade produzida historicamente (SAVIANI, 2008, pp. 13-14).

Saviani destaca neste excerto que o trabalho educativo deve ser pensado em termos de conteúdo e forma ${ }^{4}$. No que responde aos conteúdos, considera que a noção de clássico seja um critério central, já que clássico é algo que se mantém vivo na história precisamente por ser sempre necessário. $O$ desenvolvimento histórico da prática social destacado acima se constitui como um movimento dialético - já que duplamente determinado - entre necessidade e atividade, no qual alguns traços se tornam elementos intrínsecos ao gênero humano, ultrapassando os limites temporais do momento de sua produção e se mantendo como um aspecto chave do desenvolvimento da humanidade. Marx já destacara essa elevação de um conteúdo humano para além do momento histórico de sua produção, incorporando-se como parte de nosso patrimônio genérico; para tanto, utiliza-se justamente da arte como objeto de análise:

De outro lado: é possível Aquiles com pólvora e chumbo? Ou mesmo a llíada com a imprensa ou, mais ainda, com a máquina de imprimir? Com a alavanca da prensa, não desaparecem necessariamente a canção, as lendas e a musa, não desaparecem, portanto, as condições necessárias da poesia épica?

\footnotetext{
${ }^{4}$ Destaque-se aqui os avanços nos elementos didáticos da pedagogia histórico-crítica, que articularam os conteúdos escolares e as formas de ensino destes conteúdos às especificidades do destinatário desse processo educacional, principalmente a partir das contribuições da psicologia histórico-cultural (GALVÃO; LAVOURA; MARTINS, 2019).
} 
Mas a dificuldade não está em compreender que a arte e o epos gregos estão ligados a certas formas de desenvolvimento social. A dificuldade é que ainda nos proporcionam prazer artístico e, em certo sentido, valem como norma e modelo inalcançável (MARX, 2011, p. 63 , grifos nossos).

A poesia épica grega é uma produção cultural da humanidade que vem sendo preservada - reproduzida, praticada, consumida - há mais de dois milênios. Por outro lado, diversos traços da sociedade que deu origem a esta expressão artística já há muito não se encontram nas formações sociais posteriores, principalmente àquela em que vivemos nossa vida cotidiana. Mas, como destaca Marx, o ponto chave deste fato não está em compreender que uma expressão artística tenha sua origem numa sociedade de uma dada época, que reflita elementos que permeiam a subjetividade de determinada formação social; a grande questão a ser observada é que ela ainda possa ser experienciada numa formação social tão diferente daquela em que teve origem, que ainda proporcione um efeito estético de identificação entre a subjetividade individual e os elementos refletidos em seus versos.

A formulação da problemática proposta por Marx nos explicita algumas especificidades da categoria de clássico na arte. O caráter necessariamente subjetivo, típico da arte como reflexo antropomórfico da realidade - e não como na ciência, reflexo da realidade em si mesma, embora sempre construído por seres humanos concretos -, faz com que a significação de uma determinada prática artística no interior da prática social seja sempre uma experiência, uma vivência de determinados elementos da nossa vida que estão refletidos na obra.

Essa constatação é decisiva para a compreensão da arte como conteúdo escolar. Tomemos um exemplo: o papel crítico da obra de Chico Buarque para a formação de uma consciência acerca do período ditatorial brasileiro (1964-1985). O grande diferencial da canção de Chico não está em proporcionar o entendimento deste período tal qual o estudo da História ou da Sociologia nos propiciam ao refletirem, de maneira científica, os fatos ocorridos e as relações entre estes fatos; a riqueza específica de sua música, seu grande papel para a formação da consciência, é que por meio dela podemos sentir a ditadura, e nessa vivência elevamos nosso nível de consciência sobre este momento histórico - pense-se em sua canção Acorda amor: "Acorda amor/ Eu tive um pesadelo agora/ Sonhei que tinha gente lá 
fora/ Batendo no portão, que aflição/ Era a dura, numa muito escura viatura/ Minha nossa santa criatura/ Chame, chame, chame lá/ Chame, chame o ladrão, chame o ladrão" (ADELAIDE; PAIVA, 1974) . $^{5}$

A continuidade histórica de uma experiência estética, bem como seu papel na formação humana, é sempre mediada pelas características da sociedade que as vivencia (nossa experiência da llíada ou mesmo da canção de Chico Buarque é diferente daquela das pessoas que viveram no período de criação destas obras). Uma dada cultura que recebe uma dada quantidade de obras de arte irá selecionar em sua prática social aquelas importantes de acordo as "necessidades ideológicas do momento", nas palavras de Lukács (1968, p. 241). De acordo com o filósofo húngaro, "só pode conservar uma viva eficácia uma arte que possa ser sentida como reprodução do próprio passado" (idem, ibidem, grifos nossos). Essa seleção pode ser mais explícita, como no caso de uma obra em particular (Ilíada ou Chico), mas também podemos observar essa dinâmica em elementos propriamente estéticos que, de tão representativos, se incorporam ao gênero humano e se dissolvem na prática social, permeando suas expressões artísticas populares. Ariano Suassuna discute as relações entre a xilogravura, manifestação artística popular do Nordeste brasileiro, e a tradição europeia:

Para mim, porém, o mais importante de tudo era que a xilogravura popular nordestina me encantava tanto quanto aquelas artes românticas e pré-renascentistas a que me referi [...]. Entenda-se de uma vez por todas que quando falo nessas coisas não é pregando uma impossível e ridícula cruzada no sentido de "medievalizar" ou "europeizar" a cultura brasileira; é apenas por reconhecer e reencontrar tais elementos e semelhanças na cultura brasileira do povo. [...] meu encanto pelo teatro de Aristófanes, de Sófocles, de Plauto, de Shakespeare, de Goldoni, de Calderón, de Gil Vicente, ou pela novela picaresca, pela de cavalaria, pela de Cervantes e de Boccaccio vinha, mais, era do fato de eu reencontrar em tudo isso um espírito correspondente ao do Sertão, do Nordeste e do Brasil, o espírito dos romanceiros e dos espetáculos populares nordestinos; as mesmas lutas sangrentas; o épico; as vinditas familiares; os casos de crime, de amor e de ciúme; as fomes das grandes secas e epidemias, com seus cortejos de miséria, sofrimento e morte; as legendas; a crítica social; as burlas; o

\footnotetext{
${ }^{5}$ O compositor Julinho da Adelaide corresponde a um heterônimo adotado por Chico Buarque para burlar a censura vigente no período ditatorial brasileiro.
} 
ódio; o riso violento e desmedido - tudo isso alçado, porém, às alturas do poético, do trágico e do cômico, pela força arrebatadora e transfiguradora do mítico (SUASSUNA, 2008, pp. 214-215).

Ao aproximar a prática da xilogravura aos grandes clássicos da literatura e do teatro europeus, Suassuna não está subjugando uma à outra. Trata-se somente da identificação de elementos subjetivos em comum entre a cultura europeia e a cultura popular brasileira, elementos que se mantêm vivos como substrato da prática artística popular, se expressando sob diferentes formas, tais como a xilogravura. Ao analisar precisamente este excerto, Santos destaca o caráter clássico destes elementos:

Percebe-se que Suassuna buscava no particular (leia-se, principalmente, no sertão nordestino) o universal (como já tinha feito o próprio Guimarães Rosa). Não se tratava de apostar num revival de uma espécie de Idade Média perdida brasileira, mas sim de valorizar o que existia de "clássico" na arte popular e tradicional do Nordeste. E mais, a obra de Ariano Suassuna e do Movimento Armorial não pode ser interpretada pelos extremos: ou só pela sua supervalorização da "cultura popular genuína", ou por um caráter excessivamente erudito - ou mesmo, para seus maiores críticos, como elitista e conservadora. É preciso encarar de uma maneira não maniqueísta o processo de formação e recriação do Armorial. Ele foi demarcado no tempo e no espaço, possuindo contradições e limitações, contudo deixou um legado significativo sobre o que entendia e o que pretendia preservar sob a denominação de "cultura popular" (SANTOS, 2017, p. 190).

Em sua análise, Santos não está investigando o potencial formativo da obra de Suassuna e do Movimento Armorial; mesmo assim, a noção de clássico aplicada pela autora nos parece bastante semelhante àquela que orienta a seleção dos conteúdos escolares na pedagogia histórico-crítica. Suassuna buscava identificar os elementos clássicos nas manifestações artísticas da cultura popular nordestina e, para isso, observava suas relações históricas e estéticas com a cultura europeia. Elementos que correspondem a uma universalidade humano-genérica, que ultrapassam os limites de uma cultura em particular. Por outro lado, estes elementos não se assemelham a leis abstratas que determinam práticas artísticas populares; eles sempre serão mediados pelos traços particulares de cada 
formação social, que os incorpora como substrato de suas expressões artísticas - note, o leitor, que o próprio Suassuna considera que seu "encanto" pela tradição europeia está no fato de "reencontrar em tudo isso um espírito correspondente ao do Sertão, do Nordeste e do Brasil", e não o contrário.

A visão de Suassuna sobre as relações entre a cultura popular brasileira e a cultura erudita europeia podem contribuir para a seleção dos conteúdos escolares na medida em que se orienta pelos elementos clássicos que permeiam ambas. Entretanto, neste momento devemos retomar um pressuposto fundamental ressaltado acima: é necessário que percebamos que a análise de Suassuna se refere à prática artística em si mesma, e não como conteúdo escolar; para que ela se torne um conteúdo escolar necessitamos selecionar e sistematizar esses elementos clássicos, de modo que, pela via da prática pedagógica, sejam incorporados como segunda natureza (SAVIANI, 2008), constituindo o substrato de nossa prática artística, que refletirá elementos da nossa subjetividade.

Sem adentrar uma análise mais detalhada, a qual tivemos a oportunidade de realizar em outro trabalho (ABREU; DUARTE, 2020), vejamos um exemplo de conteúdo escolar clássico da área da música: a notação musical. A importância decisiva da aquisição da capacidade de escrita e leitura da música para a formação não é um consenso entre os educadores musicais, os quais, apoiados no fato de que muitas manifestações musicais populares - extremamente ricas! - são praticadas e se reproduzem sem a mediação da notação, reduzem o papel de seu aprendizado, considerando-a como regras abstratas que não expressam a riqueza musical da prática popular.

Tais críticos não percebem, entretanto, que mesmo as manifestações artísticas populares carregam traços e elementos estéticos do desenvolvimento histórico de toda cultura ocidental. Quase a totalidade das práticas musicais populares de nosso tempo - sejam elas "tradicionais" ou já no contexto da cultura industrializada - se configura a partir do chamado sistema tonal ${ }^{6}$. Mas a tonalidade só pôde surgir e se dissolver na prática social como forma de organização musical geral a partir do

\footnotetext{
${ }^{6}$ De maneira bem simplificada, a música tonal é aquela na qual a organização musical ocorre sobre o princípio geral das relações de tensão (dominante) e relaxamento (tônica) que se formam a partir de uma determinada hierarquia das notas musicais que giram em torno de um mesmo centro tonal.
} 
desenvolvimento da polifonia ${ }^{7}$, a qual, por sua vez, tem sua base na música escrita; como nos explicam Grout e Palisca "é certo que a polifonia enquanto tal não é exclusivamente ocidental, mas foi a nossa música que, mais do que qualquer outra, se especializou nessa técnica" (GROUT; PAULISCA, 1994, p. 96), e isso está diretamente relacionado com o surgimento da notação musical. Ressalte-se, ainda, que todos estes processos de desenvolvimento ocorreram em um ambiente extremamente restrito: os monastérios europeus, na passagem da Idade Média para o Renascimento, que concentravam os saberes sistematizados à época; ou seja, um ambiente em quase nada semelhante ao nosso cotidiano na atualidade.

Nesse sentido, tomar a notação musical como conteúdo escolar não se reduz ao ensino da capacidade de executar uma partitura; trata-se de algo muito mais profundo, ligado às relações conscientes entre o indivíduo e sua prática musical. Uma pessoa pode perfeitamente realizar uma prática musical de maneira rica e elaborada sem a mediação da notação - o que, na maioria das vezes, é o que acontece na prática social da música. Contudo, isso não quer dizer que essa música praticada não possa ser escrita e, principalmente, que por meio dessa escrita possamos perceber os elementos que a estruturam. Assim, a aprendizagem da notação musical significa a reprodução, na subjetividade da individual, dos elementos presentes na estrutura da música. Tal incorporação dos elementos historicamente desenvolvidos de expressão musical leva-nos a uma relação mais consciente com a nossa música.

Acreditamos que o exemplo da notação musical como conteúdo da educação escolar, isto é, sua condição de clássico - entendendo a categoria de clássico nos termos também discutidos acima - pode abrir caminhos teóricos e metodológicos para a seleção dos conteúdos escolares da arte na perspectiva da pedagogia histórico-crítica. Cabe ressaltar, contudo, que este é somente um dos momentos da organização da prática pedagógica da arte na escola: como vimos, é necessário que avancemos também nas formas de seu ensino, tomando como referência o destinatário desse processo educacional. Para a pedagogia histórico-crítica a efetivação destes

\footnotetext{
${ }^{7}$ Também de maneira simplificada, a polifonia corresponde ao desenvolvimento ocidental da técnica composicional, que deixa de estar centrada em uma única linha melódica-temática (voz), para progressivamente trabalhar com duas ou mais vozes que, no entanto, devem preservar sua identidade melódica e rítmica individual.
} 
pressupostos na prática social tem como horizonte a transformação dessa prática.

\section{Catarse: relações entre os conteúdos escolares da arte e a transformação da prática social}

O salto qualitativo nas relações entre o indivíduo e a música que ocorre quando este se apropria da notação musical, tornando-a segunda natureza, demonstra, a nosso ver, o chamado fenômeno da catarse, considerado pela pedagogia histórico-crítica como "o ponto culminante do processo educativo" (SAVIANI, 2018, p. 58). Trata-se da confirmação do trabalho educativo como movimento de produção da humanidade nos seres humanos, da realização da especificidade da prática educativa como prática social.

Dissemos que a importância da aprendizagem da escrita e da leitura da música está ligada à relação consciente que se estabelece entre o indivíduo e a estrutura da sua própria prática musical. A noção de catarse adotada pela pedagogia histórico-crítica é aquela "entendida na acepção gramsciana de 'elaboração superior da estrutura em superestrutura na consciência dos homens'” (idem, p. 57), ou, como reflexo, como formas de reprodução ideativa da essência da realidade objetiva concreta na subjetividade individual. A necessidade de se tomar consciência acerca da realidade, incluindo-se aí nossa própria prática social, decorre, antes de mais nada, da natureza do trabalho, em que produtos da atividade humana objetivam-se na realidade, constituindo-se parte dela, condicionando as necessidades e possibilidades de ação dos próprios seres humanos; esse condicionamento faz com que os indivíduos ajam sem necessariamente estarem conscientes das características essenciais de sua ação, simplesmente respondendo às necessidades imediatas da prática social; nas palavras de Marx, "fazem isto sem o saber" (MARX, 2013, p. 96). De acordo com Duarte

Assim como os meios e os produtos da atividade humana se constituem em objetivações do gênero humano, o mesmo ocorre com as relações entre as pessoas. Essas relações objetivam-se, e cada indivíduo depara-se com eles já existentes, tendo que delas se apropriar para poder viver. Na sociedade alienada, essa apropriação das relações sociais objetivadas realiza-se, na maioria dos casos, na forma de uma 
apropriação espontânea, isto é, as pessoas assumem naturalmente as relações sociais, não se dando conta, na maior parte das vezes, do caráter histórico e, portanto, mutável dessas relações. As relações sociais assumem a aparência de forças naturais às quais os indivíduos se submetem, interiorizando-as por meio de uma identificação espontânea com a situação dada. Tais relações, na história humana até aqui percorrida, não têm sido reconhecidas pela maior parte da humanidade, e na maior parte das situações, como produtos da atividade histórica humana. É condição indispensável para a realização da plena liberdade do gênero humano que os seres humanos submetam as relações sociais objetivados ao seu controle consciente (DUARTE, 2013, p. 80).

Mas este processo de elevação das relações sociais objetivadas na estrutura da sociedade à consciência individual não significa que elas tenham sido hipostasiadas, transformadas em entidades metafísicas que dominam o indivíduo levando-o ao reino mágico da consciência. Trata-se tão somente de uma questão prática: da relação consciente com determinada prática social que existe objetivamente em si na realidade que se manifesta quando transformamos nossa própria prática individual. Daí que Saviani observe a catarse simultaneamente como uma "efetiva incorporação de instrumentos culturais", os quais, uma vez internalizados, tornados segunda natureza do indivíduo, são transformados em "elementos ativos da transformação social" (SAVIANI, 2018, p. 57). Isso quer dizer que a catarse não se resume a uma apropriação dos elementos sociais objetivados, mas refere-se também às mudanças objetivas da prática. Como nos mostra Marx, o movimento de apropriação da realidade objetiva pelo ser humano é simultaneamente subjetivo e objetivo:

[...] a apropriação sensível da essência e da vida humanas, do ser humano objetivo, da obra humana para e pelo homem, não pode ser apreendida apenas no sentido da fruição imediata, unilateral, não somente no sentido da posse, no sentido do ter. O homem se apropria da sua essência omnilateral de uma maneira omnilateral, portanto como um homem total. Cada uma das suas relações humanas com o mundo, ver, ouvir, cheirar, degustar, sentir, pensar, intuir, perceber, querer, ser ativo, amar, enfim todos os órgãos da sua individualidade, assim como os órgãos que são imediatamente em sua forma como órgãos comunitários, são no seu comportamento objetivo ou no seu comportamento para com o objeto a apropriação do mesmo, a apro- 
priação da efetividade humana, seu comportamento para com o objeto é o acionamento da efetividade humana [...] (MARX, 2010, p. 108 , grifos no original).

A categoria de catarse expressa o processo de formação de uma segunda natureza do ponto de vista processual, explicitando os movimentos e dinâmicas envolvidos na incorporação do que é externo. Observando a catarse como prática, tal atividade de apropriação aparecenos claramente não só do seu ponto de vista subjetivo, isto é, da perspectiva do indivíduo que se apropria da realidade; nas palavras de Marx, "somente no sentido da posse, no sentido de ter". Revela-se também seu caráter objetivo, a apropriação como prática de apropriação, como "comportamento para com o objeto". Assim, a segunda natureza não se manifesta de outra maneira senão na própria prática deste indivíduo, pois ela não é um elemento puramente abstrato, puramente metafísico, e sim um traço da sua individualidade. A incorporação existe na medida em que nossa prática é transformada, ou seja, em que manifesta aqueles traços essenciais da realidade objetiva que agora são nossos próprios traços, nossa própria natureza.

A transformação da prática social proporcionada pela catarse ocorre também de maneira específica no que corresponde à arte. Essa especificidade está ligada ao movimento dialético que se estabelece entre a arte e a vida cotidiana: ao mesmo tempo em que a experiência da arte nos eleva a níveis afetivos que não conseguimos alcançar na vida cotidiana onde normalmente somos obrigados a agir de maneira imediatista, pragmática, e onde as possibilidades de experiência afetiva são muito limitadas -, essa elevação não significa um distanciamento perante a vida, mas sim uma aproximação profunda em seus elementos essenciais, aproximação a uma riqueza afetiva que está presente na prática social, mas que a própria prática social nos impede de vivenciar. Como explica Lukács (1967, p. 76):

Em sua concepção mais geral a catarse significa, pois, que um fenômeno ou um grupo de fenômenos refigurados, preservando sua íntima verdade vital, crescem por cima do nível alcançável da vida cotidiana. Esta elevação, facilitada pela mimese estética, acima do normalmente acessível, está ligada à consciência de que se trata, apesar de tudo, somente do cumprimento extremo de possibilidades humanas 
perfeitamente delimitadas, e não do jogo charlatanesco de uma "salvação" em qualquer transcendência.

A catarse na arte proporciona a fusão da vida afetiva individual à riqueza afetiva que emana e acompanha o desenvolvimento do gênero humano sem, contudo, abandonar a singularidade de cada indivíduo, pois trata-se da vida afetiva de um indivíduo real, de sua vida afetiva - daí que a experiência imediata seja um traço decisivo da catarse artística, como já discutido acima acerca da continuidade histórica da llíada ou dos elementos que compõem o substrato da prática da xilogravura. Mas embora, principalmente na arte, a singularidade da experiência seja um aspecto central, observar de maneira imediatista a catarse pode reduzi-la a um momento virtuoso e inebriante de tomada de consciência. Lukács aponta a necessidade de compreendermos a catarse na arte para além do imediatismo de uma experiência singular, destacando as relações extremamente indiretas entre o antes e o depois da vivência estética para a transformação de um indivíduo:

Naturalmente, a eficácia social e humanista da arte não consiste apenas numa embriaguez da receptividade direta. Esta eficácia tem um antes e um depois; um dos principais erros cometidos pela maior parte dos teóricos idealistas da estética é o de isolar esta eficácia imediatamente artística da vida global do sujeito receptivo. Nenhum homem se torna diretamente outro homem no prazer artístico e através dele. $O$ enriquecimento obtido neste caso é um enriquecimento da sua personalidade, exclusivamente dela. Mas tal personalidade é determinada em um sentido classista, nacional, histórico etc. (além de ser, no interior destas determinações, formada por experiências pessoais) sendo também uma vazia ilusão de estetas a convicção de que existe um só homem que possa receber como tabula rasa espiritual uma obra de arte. Não, todas as suas experiências precedentes, que vivem nele sobre a base de sua determinação social, permanecem operantes durante o prazer estético. Mesmo reconhecendo em todo o seu valor a força evocadora da forma artística, deve estar claro que qualquer sujeito receptivo coloca incessantemente em confronto a realidade refletida pela arte com as experiências que ele mesmo adquiriu (LUKÁCS, 1968, p. 292, grifos do autor). 
O filósofo húngaro discute aqui sobre a impossibilidade de se estabelecer uma relação direta de causa e consequência entre o antes e o depois da experiência estética, como se essa experiência culminasse invariavelmente em determinado comportamento do indivíduo perante a realidade objetiva. Na verdade, trata-se de um processo altamente mediado entre duas totalidades: a primeira, o indivíduo concreto, síntese de múltiplas determinações, o ser individual formado a partir de todas as suas experiências biográficas singulares, as quais, obviamente, possuem determinações mais gerais; a segunda, a obra de arte, que sintetiza as principais determinações da realidade objetiva em uma forma sensível, capaz de elevar a subjetividade humana a níveis incapazes de serem atingidos na vivência cotidiana. Assim, a passagem do antes ao depois, a transformação da prática social do indivíduo, não pode corresponder somente ao momento isolado da experiência estética; normalmente ela se dá por meio de pequenas transformações, as quais derivam de um processo de apropriação gradual da realidade objetiva e que, paulatinamente, vão se transmutando em um direcionamento ético do indivíduo. Para Duarte

Lukács chama a atenção para o fato de que as decisões de natureza ética, na maior parte das vezes, não assumem a forma de uma profunda ruptura com a visão de mundo anterior [...]. Muitas vezes, as mudanças ocorrem com uma carga emocional menor, mas, nem por isso são de valor menos decisivo para a vida do sujeito. Do meu ponto de vista, o que permite adjetivar uma mudança como catártica não é sua intensidade emocional, mas o fato de que haja uma alteração qualitativa nas relações entre a subjetividade individual e a objetividade sociocultural. Uma transformação catártica ampla e profunda pode ser gerada por um processo constituído de mudanças pequenas e quase imperceptíveis, como é o caso, na maior parte das vezes, das catarses produzidas pela atividade educativa escolar (DUARTE, 2019, p. 14).

Ora, é precisamente neste sentido que destacamos acima o papel da notação musical como conteúdo escolar, isto é, como algo que não está ligado somente à aquisição da capacidade de escrita e de leitura da música, mas principalmente pelo fato de que tal apropriação promova um salto qualitativo em nossa prática musical, transformação essa ligada ao estabelecimento de uma relação consciente com a música. Entretanto, o momento do aprendizado da notação, o feitio dos exercícios necessários 
para a apreensão deste conhecimento, dificilmente pode ser identificado imediatamente como uma catarse; esta somente se confirmará na medida em que a incorporação da notação proporcione uma experiência mais rica da prática musical.

Esta relação se torna ainda mais complexa e mediada se tentarmos estabelecer aproximações entre os conteúdos escolares e uma perspectiva mais ampla de transformação da prática social - e não somente da experiência musical. Ligações muito diretas entre o antes e o depois de um aprendizado podem levar a associações demasiadamente simplificadoras ou a dicotomias insolúveis. Por exemplo: quais as implicações do aprendizado da notação musical para a transformação da prática política de um indivíduo? Como uma pessoa aprender o que é semínima e semicolcheia ${ }^{8}$ vai contribuir para a superação das contradições inerentes ao modo de produção capitalista? E isso não é algo exclusivo das artes: quais as implicações políticas do aprendizado da química orgânica? E da equação de segundo grau? Mas, então, quer dizer que não é importante aprender essas coisas?

O que pretendemos demonstrar com tais provocações é a impossibilidade de se adotar relações muito diretas e causais entre os conteúdos escolares e a transformação da prática social, principalmente no caso da arte, já que seus conteúdos carregam, por natureza própria, a especificidade do imediatismo de uma experiência estética. Caso contrário pode-se cair numa perspectiva idealista do processo de formação humana, considerando a educação como um fenômeno que existe acima das contradições da sociedade, sendo sua única determinante. Trata-se do que Saviani caracterizou como teorias não-críticas, nas quais "concebe-se a educação com ampla margem de autonomia em face da sociedade". Tanto que lhes cabe um papel decisivo na conformação da sociedade evitando sua desagregação" (SAVIANI, 2018, p. 4), por isso "buscam compreendê-la a partir dela mesma" (idem, p. 5).

Em contrapartida, a pedagogia histórico-crítica não secundariza a importância do enriquecimento da formação humana para o processo de transformação da prática social, considerando a escola como locus por excelência de uma prática educacional revolucionária, já que se trata da forma historicamente mais desenvolvida do trabalho educativo. Ou seja, embora não possamos estabelecer reações diretas e causais entre os

\footnotetext{
${ }^{8}$ Semínima e semicolcheia são figuras da escrita musical utilizadas para representar a duração das notas.
} 
conteúdos escolares e a transformação da prática social, isso não significa que eles não sejam importantes. Nas palavras de Saviani, significa não cairmos também nas chamadas teorias crítico-reprodutivistas, que detêm "uma cabal percepção da dependência da educação em relação à sociedade", secundarizando o papel da formação e chegando "invariavelmente na conclusão de que a função própria da educação consiste na reprodução da sociedade em que ela se insere" (idem, p. 13) sem, portanto, ver possibilidade de uma educação com horizonte revolucionário.

A nosso ver, trata-se de defender a educação escolar como um elemento importante da transformação da prática social, porém reconhecendo as especificidades e os limites da prática educacional em um processo revolucionário: seu papel no processo de enriquecimento da formação dos indivíduos que promove uma relação consciente com a realidade objetiva. Como ressaltado por Saviani na análise das relações entre a educação e a política, "a função política da educação cumpre-se na medida em que ela se realiza como prática especificamente pedagógica" (idem, p. 72).

\section{Conclusão: afinal, o que significa transformar a prática social?}

Neste texto tentamos sintetizar alguns dos principais fundamentos e temas que envolvem as contribuições da arte para o desenvolvimento da prática educativa na pedagogia histórico-crítica. Com efeito, observamos o sentido ontológico que emana do desenvolvimento históricos de três diferentes esferas da prática social: a educação, a ciência e a arte, destacando a educação escolar como a forma historicamente mais desenvolvida do trabalho educativo e as especificidades da ciência e da arte como reflexos da realidade objetiva. Tal compreensão nos fornece bases para a análise da arte como conteúdo da educação escolar, apontando seus elementos clássicos. A apropriação dos conteúdos da arte pode contribuir para uma prática social transformadora, mas devemos também estar conscientes do papel particular e dos limites da prática educativa para um processo de efetiva transformação.

Cabe-nos, então, finalizar com a pergunta: transformar em quê? O que significa falar em transformação da prática social? Qual é o horizonte que nos serve de referência para tal transformação? Somente estabelecendo uma relação consciente com o objeto dessa perspectiva 
transformadora podemos compreender os elementos que dão unidade aos fundamentos da pedagogia histórico-crítica, e isso se aplica também ao ensino das artes.

Considerar um horizonte de transformação implica a ideia de um processo de desenvolvimento, um salto qualitativo perante as atuais condições da prática social. Assim, o conteúdo desse processo de transformação deve, por um lado, reconhecer as máximas possibilidades de desenvolvimento da prática social e, por outro, identificar os limites impostos para que tais possibilidades se concretizem. Como nos explica Márkus, significa superar a alienação inerente ao modo de produção capitalista, isto é, "a separação e oposição entre a essência humana e a existência humana, no sentido que Marx deu a esses termos" (MÁRKUS, 2015 , p. 115, grifos no original), criando as condições para a efetiva confirmação universal dos aspetos essenciais do gênero humano na vida de cada indivíduo.

E esta é a razão pela qual a diferenciação do capitalismo e do comunismo não é para Marx simplesmente uma distinção entre duas formações sociais sucessivas, mas representa uma diferença valorativa também. O homem é, por sua essência, um ser universal e livre que se constitui através da sua própria autoatividade, no sentido de um domínio cada vez maior da natureza e a partir de uma autonomia e consciência cada vez mais universais. Esta tendência de desenvolvimento humano afirma-se em todas as formas sociais, mas, na era da alienação universal, é válida apenas abstratamente, "em si", como característica da totalidade do progresso social [...]. Somente com a transcendência histórico-prática da alienação, a essência humana pode se tornar uma determinação concreta "para si", que caracterize os indivíduos e as comunidades. E é por esta razão que o comunismo ganha uma afirmação moral: como uma sociedade que torna possível o desenvolvimento livre simultâneo e inter-relacionado do gênero humano e dos indivíduos, e, portanto, a realização "adequada" da essência humana (MÁRKUS, 2015, pp. 117-118, grifos no original).

O horizonte da sociedade comunista é uma possibilidade real que fundamenta e dá sentido à pedagogia histórico-crítica; eliminando-se tal perspectiva, subtrai-se também toda a substância dessa corrente pedagógica. A plena formação do indivíduo não pode ser aquela que o aliena, o distancia do desenvolvimento da humanidade, mas sim aquela que 
torna a sua vida individual uma manifestação concreta da universalidade e liberdade que existem em si mesmas como características do gênero humano.

Mas se a prática social comunista é uma possibilidade concretamente dada pelas próprias contradições do capitalismo, é também verdade que um indivíduo consciente de sua relação com o gênero humano depende de um processo de formação, o que implica posicionamentos acerca dos conteúdos a serem apropriados pelo indivíduo. As práticas educacionais que visem a superação do capitalismo, então, devem levar em conta a relação dialética entre o horizonte de uma individualidade concretamente universal e as possibilidades dessa concretização existentes no interior da sociedade capitalista. Para Duarte (2013, p. 195)

\begin{abstract}
Esta deve ser a linha mestra das ações dos educadores alinhados à pedagogia histórico-crítica: lutar para que se torne cada vez mais in tensa em todos os indivíduos a necessidade de socialização dessa produção material e espiritual universal. A revolução comunista nasce dessa contradição entre o fato de a maioria das pessoas não poder se apropriar das objetivações do gênero humano e o caráter universal e multifacetado da riqueza material e espiritual produzida pelo trabalho dos próprios seres humanos. Uma pedagogia que valorize a liberdade dos indivíduos não será aquela que tenha por objetivo formar nos alunos a capacidade de adaptação à realidade local da qual eles fazem parte, mas, sim, aquela que forme nos alunos a consciência da necessidade de apropriação da riqueza espiritual universal e multifacetada, que vem sendo criada, mesmo que contraditoriamente, na própria sociedade burguesa.
\end{abstract}

À educação escolar, como forma historicamente mais desenvolvida do trabalho educativo, cabe socializar a riqueza espiritual construída pela totalidade da prática humana visando a plena identificação entre o ser individual e essa riqueza. A arte, como uma dimensão da educação escolar, não foge a esta lei geral: cabe à escola socializar o conhecimento sistematizado da arte, as formas mais ricas da produção artística da humanidade. Como vimos, isso depende de um duplo movimento: por um lado, da identificação dos conteúdos a serem apropriados, que exige o exame racional do processo histórico de produção e reprodução da prática artística em suas diferentes modalidades e expressões para a captação de seus elementos clássicos; por outro lado, depende também das formas de 
se garantir a apropriação desses elementos por cada indivíduo singular, constituindo o fundamento e o sentido de sua própria prática artística.

\section{Referências}

ABREU, Thiago Xavier de; DUARTE, Newton. A notação musical e a relação consciente com a música: elementos para refletir sobre a importância da notação como conteúdo escolar. Revista da ABEM, v. 28, p. 65-80, 2020. ADELAIDE, Julinho da; PAIVA, Leonel. Acorda amor. Intérprete: Chico Buarque. In: BUARQUE, Chico. Sinal fechado. Philips/Universal Music, 1974. Faixa 7.

DUARTE, Newton. Lukács e Saviani: a ontologia do ser social e a pedagogia histórico-crítica. In: SAVIANI, Dermeval; DUARTE, Newton. Pedagogia histórico-crítica e luta de classes na educação escolar (Orgs.). Campinas, SP: Autores Associados, 2012.

DUARTE, Newton. A Individualidade Para-Si: contribuição a uma teoria histórico-social da formação do indivíduo. 3ae ed. rev. Campinas: Autores Associados, 2013.

DUARTE, Newton. A catarse na didática da pedagogia histórico-crítica. ProPosições, Campinas, SP. v. 30, 2019.

GALVÃO, Ana Carolina; LAVOURA, Tiago Nicola; MARTINS, Lígia Márcia. Fundamentos da didática histórico-crítica. 1a ed. Campinas, SP: Autores Associados, 2019.

GROUT, Donald J.; PALISCA, Claude V. História da música ocidental. Lisboa: Gradiva, 1994.

KIRALYFALVI, Bela. Lukács's Views on Artistic Freedom. Leonardo, vol.16, n.2. spring, 1983, pp. 124-126.

LUKÁCS, György. Estética: la peculiaridad de lo estético. Cuestiones preliminares y de principio. Tradução: Manuel Sacritán. Barcelona: Grijalbo, 1966. v.1.

LUKÁCS, György. Estética: la peculiaridad de lo estético. Cuestiones liminares de lo estético. Traducción: Manuel Sacritán. Barcelona: Grijalbo, 1967. v.4. 
LUKÁCS, György. Introdução a uma estética marxista. 2.ed. Rio de Janeiro: Civilização Brasileira, 1968.

MÁRKUS, György. Marxismo e Antropologia: o conceito de 'essência humana' na filosofia de Marx. São Paulo: Expressão Popular, 2015.

MARTINS, Lígia Marcia. 0 desenvolvimento do psiquismo e a educação escolar: contribuições à luz da psicologia histórico-cultural e da pedagogia histórico-crítica. Campinas, SP: Autores Associados, 2013.

MARX, Karl. Manuscritos Econômico-Filosóficos. Tradução: Jesus Ranieri. 4a reimpressão. São Paulo: Boitempo, 2010.

MARX, Karl. Grundrisse: manuscritos econômicos de 1857-1858: esboços da crítica da economia política. Tradução: Mario Duayer, Nélio Schneider. São Paulo: Boitempo, 2011.

MARX, Karl. O Capital: crítica da economia política: Livro I: o processo de produção do capital. Tradução: Reginaldo Sant'Anna. Rio de Janeiro:

Civilização Brasileira, 2013.

MARX, Karl; ENGELS, Friedrich. A ideologia alemã. Tradução: Rubens Enderle, Nélio Schneider, Luciano Cavini Martorano. São Paulo: Boitempo, 2007.

SAVIANI, Dermeval. Educação e questões da atualidade. São Paulo: Livros do Tatu e Cortez, 1991.

SAVIANI, Dermeval. Pedagogia histórico-crítica: primeiras aproximações. 10 a ed. Campinas: Autores Associados, 2008.

SAVIANI, Dermeval. Escola e democracia. 43a ed. rev. Campinas: Autores Associados, 2018.

SANTOS, Nívea Lins. O Quinteto Armorial e sua relação com a modernidade brasileira (1974-1980). ArtCultura, Uberlândia, v. 19, n. 35, p. 185-202, jul.dez. 2017.

SUASSUNA, Ariano. Almanaque armorial. Organização de Carlos Newton Júnior. Rio de Janeiro: José Olympio, 2008. 